Cultura e música popular 



\section{Culturas populares no presente: fomento, salvaguarda e devoração}

ALBERTO T. IKEDA I

Para Elizabeth Travassos (1955-2013), in memoriam.

\section{Introdução}

$\longrightarrow$ UANDO lemos textos enfocando as culturas nos últimos anos, comumente encontramos discussões sobre globalização, mundialização, multiculturalismo, pluralismo, estandartização, ecletismo e outros assuntos, vinculados aos aspectos econômicos, industriais e cultural-cibernético-comunicacionais da chamada pós-modernidade. No Brasil, e certamente em outros países, concomitante a essas discussões, após a década de 1980, as preocupações também se voltaram para as questões ambientais, como se verificou na proliferação das Organizações Não Governamentais $(\mathrm{ONG}){ }^{1}$ disseminadas sob a inspiração de eventos como a Conferência das Nações Unidas sobre o Meio Ambiente e o Desenvolvimento, conhecida como Eco-92 ou Rio-92, ocorrida no Rio de Janeiro. Nela também foram incluídas propostas de respeito às culturas tradicionais e à diferença cultural. Por sua vez, desde aquela época, estamos marcados por preocupações do âmbito político-social relacionadas a pobreza, educação, saúde e moradia, e ao direito à cultura, chegando-se às iniciativas identificadas como ações afirmativas, de inclusão social, da cultura de resistência e outras nomenclaturas. Muitos desses eventos centraram-se no envolvimento com as culturas locais, étnicas e populares tradicionais, que são o foco de atenção do presente texto, concentrando-se no Brasil. Abrangemos sobretudo o período entre o final da década de 1980 e os anos seguintes, quando ocorreu significativo movimento de retomada do interesse por essas expressões culturais de tradição oral. ${ }^{2}$ Elas são identificadas também como cultura popular, cultura tradicional, cultura popular de tradição oral, cultura de raiz, tradições populares, conhecimentos tradicionais, e ainda folclore, que é o termo mais consagrado historicamente, desde meados do século XIX. A nomenclatura folclore, no entanto, tem sido evitada por muitos pesquisadores nos últimos tempos por seu desgaste semântico. ${ }^{3}$ Recentemente esses mesmos fatos culturais passaram a ser categorizados também como patrimônio imaterial, conforme aparece na Constituição Federal de 1988, que inclui como Patrimônio Cultural Brasileiro "os bens de natureza material e imaterial", e dois anos depois oficializou-se o Decreto n.3.551, de 4 de agosto de 2000, instituindo o Registro de Bens Culturais de Natureza Imaterial, criando-se o Programa Nacional do Patrimônio Imaterial. ${ }^{4}$ 
As inúmeras denominações são tentativas de conferir a esses saberes populares alguma característica ou distinção, buscando singularizá-las, diferenciando-as de outras formas, como as da cultura de massa, da cultura urbana moderna e da cultura "erudita" e até da cultura indígena. Porém, a tarefa não é simples, pois os conhecimentos abarcados nas culturas populares tradicionais são muito diversificados, além do que comumente uma mesma modalidade pode ter diferenças - na forma, função e até significados - em regiões e/ou grupos distintos. Entre nós, essas expressões culturais tradicionais obtiveram bem mais visibilidade no decênio de 1990. Entretanto, é importante lembrar que a atenção para esse conjunto de conhecimentos populares tem um lastro já histórico, vindo, de modo mais evidente, desde o século XIX, em alguns países da Europa. Desde então, as anteriormente denominadas "antiguidades populares" ou "literatura popular", passaram a ter reconhecimento. Embora o hábito de coletar costumes populares ocorresse desde épocas bem anteriores, o movimento teve impulso programático mais especificamente a partir de meados do século XIX, com a proposta de criação do termo: folk-love, na Inglaterra, em $1846,{ }^{5}$ referindo-se ao "saber tradicional do povo" ou à "sabedoria popular". O autor da proposição, William John Thoms, solicitava na ocasião apoio para a realização de levantamento sobre "usos, costumes, cerimônias, crenças, romances, rifões, superstições etc., dos tempos antigos" (cf. Della Mônica, 1976, p.15), que estavam, então, "inteiramente perdidos" e se preocupava com o quanto "se poderia ainda salvar...", diante da modernização. ${ }^{6}$

Ao longo da história são muitas as tentativas de se definir a cultura popular tradicional, sobretudo por folcloristas. Porém, trata-se de tarefa complexa, com resultados que sempre apresentam um ou outro senão, por envolverem saberes e fazeres tão variados. Aqui, apenas para efeito de um balizamento conceitual, podemos recuperar dois textos mais recentes que têm grande consagração por serem emitidos por organização de alcance e reconhecimento mundial, a Organização das Nações Unidas para a Educação, a Ciência e a Cultura (Unesco), que tem sido uma referência importante para os países no que se refere às reflexões sobre a cultura. Em um documento de 1989, define-se:

A cultura tradicional e popular é o conjunto de criações que emanam de uma comunidade cultural fundadas na tradição, expressadas por um grupo ou por indivíduos e que reconhecidamente respondem às expectativas da comunidade enquanto expressão de sua identidade cultural e social; as normas e os valores se transmitem oralmente, por imitação ou de outras maneiras. Suas formas compreendem, entre outras, a língua, a literatura, a música, a dança, os jogos, a mitologia, os ritos, os costumes, o artesanato, a arquitetura e outras artes. ${ }^{7}$

Mais recentemente, em 2003, a mesma organização estabeleceu um outro conceito relacionado ao anterior, o de patrimônio imaterial, definido como:

os usos, representações, expressões, conhecimentos e técnicas - junto com os instrumentos, objetos, artefatos e espaços culturais que lhes são inerentes - 
que as comunidades, os grupos e em alguns casos os indivíduos reconhecem como parte integrante de seu patrimônio cultural. ${ }^{8}$

Note-se que também é um conceito bastante “aberto", podendo ser aplicado a muitos fatos culturais, de diversos tipos de sociedades, mas que na prática, entre nós, tem sido relacionado predominantemente aos saberes das culturas populares e tradicionais.

$\mathrm{Na}$ primeira definição destacam-se ideias como: conjunto de criações (vários fatos), emanação comunitária, embasamento na tradição, expressão de grupo ou individual, reconhecimento comunitário, expressão de identidade e transmissão oral, incluindo-se vários exemplos de fenômenos culturais que são abarcados na definição aos quais se podem acrescentar muitos mais. No segundo, ressaltam-se os aspectos intangíveis da cultura, além dos seus correspondentes resultados materiais e os espaços físicos onde ocorrem. São peculiaridades que costumam ser destacadas quando se procura identificar os saberes da cultura popular tradicional. ${ }^{9}$

\section{A presença das culturas populares}

Além, evidentemente, da presença nas próprias comunidades mantenedoras das expressões culturais que aqui nos interessam, envolvendo sobretudo músicas, festas, rituais e danças, em seus calendários específicos, o atual movimento de atração por elas promove as suas presenças, em formatos diversos, em outros cenários da cultura, em apresentações públicas, como: centros culturais, bibliotecas, universidades, ${ }^{10}$ teatros, escolas de ensino fundamental e atividades de inclusão social (ONG), ruas e praças, nas televisões, casas noturnas, clubes e até bares e festas particulares, sendo também veiculadas por meio de CD e documentários (televisões, rádios e cinemas).

A aproximação com os saberes populares aparece até na gastronomia e na moda, nas roupas, cabelos e adornos corporais (look étnico, bijuteria ou biju étnica, estampa étnica), setores nas quais as referências às culturas de tradição oral estão presentes.

Assim, em alguns segmentos sociais vive-se uma “onda” etnicista - uma época de verdadeira fascinação pelo étnico -, podemos dizer, de incorporação das culturas de povos diversos, genericamente assim identificados, envolvendo também as culturas populares tradicionais. O interesse maior por essas expressões se dá entre estudantes, artistas (músicos, atores, dançarinos), educadores, pesquisadores acadêmicos, produtores culturais, jornalistas, profissionais envolvidos com questões sociais e outros. Nesse aspecto, podem-se encontrar em várias cidades do Brasil grupos de "projeção folclórica" de música e/ou danças / folguedos compostos comumente por estudantes, da mesma forma como se verifica em determinados grupos tradicionais ultimamente boa quantidade de jovens não ligados comunitariamente ou familiarmente a estes, que comumente são identificados como "universitários". No primeiro caso, podemos mencionar a existência de "maracatus" (modelados nos grupos de Pernambuco) ou mais 
precisamente de grupos instrumentais de música ("banda de percussão") de maracatu em cidades como São Paulo, Rio de Janeiro, Brasília, Campinas (SP), Florianópolis e muitas outras, inclusive em cidades da Europa (França, Alemanha, Irlanda, Inglaterra, Itália, Espanha, Áustria e Suíça). ${ }^{11}$

No que se refere especificamente à música, por sua vez, nunca se viu antes tão grande quantidade de CD e videodocumentários de música/cultura tradicional como os lançados nesses anos, por instituições de diversos tipos (departamentos e secretarias governamentais, ONG, Fundações e Associações Culturais, selos privados), inclusive pelos próprios grupos tradicionais, com apoio financeiro governamental e privado, conforme se verificava nas lojas de comércio especializadas em "discos", nas quais se podiam encontrar músicas de muitas partes do mundo e do Brasil, nas sessões denominadas: world music, música étnica, música do mundo ou música internacional. ${ }^{12}$

Outra vertente reveladora do encantamento pelas "sonoridades tribais" ou música "de mundos esquecidos"13 se confirmou nas programações de algumas emissoras de televisão, sobretudo educativas ou "a cabo" (que começaram a proliferar no Brasil principalmente a partir de meados da década de 1990), exibindo documentários sobre a cultura de povos diversos, muitas vezes na forma de viagens de aventura, revelando fatos culturais, curiosos e exóticos (festas, danças e músicas), incluindo aspectos da natureza e da vida animal. No tocante às televisões educativas, podemos exemplificar com a série de videodocumentários: Bahia, singular e plural, produzidos, a partir de 1998, pelo Instituto de Radiodifusão da Bahia (IRDEB), uma fundação da Secretaria da Educação do Estado, que se fez acompanhar de uma série de CD. Os vídeos foram veiculados pela TV Educativa da Bahia, TV Cultura de S. Paulo e a TV Senado. Em 2002 a série já contava 14 títulos e outros continuavam sendo produzidos. Mas a divulgação de documentários etno-cultural-musicais extrapola as televisões educativas. Também verificou-se em alguns casos a adesão mais comercial por essa vertente musical, como o exemplo de uma série de quinze programas (documentários de 30 minutos), denominada "Música do Brasil", veiculada, sintomaticamente, pela MTV (Music Television) brasileira, semanalmente, a partir de abril de 2000, apresentando um amplo mapeamento das práticas musicais no Brasil, notadamente as tradicionais. Como se sabe, a MTV sempre se voltou mais para o "público jovem", dedicando-se principalmente à música pop-rock. $\mathrm{O}$ documentário foi iniciativa de uma empresa privada ligada ao setor das comunicações. Nas emissoras comerciais, outro exemplo da generalização da simpatia pelas culturas populares ocorreu no Programa Especial veiculado na TV Globo, na noite de Natal de 24 de dezembro de 2005 (sábado), às 21h55, intitulado: Xuxa Especial de Natal: As folias de Natal no Brasil, apresentando diversos folguedos populares tradicionais, com músicas, danças e encenações (marujada, reisado, boi de reis etc.), intercalados com cantores como Milton Nascimento, Carlinhos Brown e Elba Ramalho, sabendo-se que a apresentadora Xuxa Meneghel sempre se dedicou ao repertório pop infantil. 
Nas instituições culturais e de entretenimento, houve, igualmente, aumento na programação de "espetáculos de cultura popular". Demonstração disso são os eventos realizados no Serviço Social do Comércio (Sesc), em todo o Brasil, e até mesmo em algumas casas noturnas "alternativas" e festas particulares. Tanto são programados artistas que criam suas próprias composições com base nas referências tradicionais, como são incluídos os próprios grupos tradicionais, muitas vezes em um mesmo espetáculo, em junção que não se concebia em outras épocas, conforme ocorreu na Programação "Balaio Brasil", organizada pelo Sesc-São Paulo, em novembro de 2000, quando "cerca de 150 atrações divididas entre Teatro, Dança, Música, Literatura e Artes Visuais" foram apresentadas em várias unidades, "desde produções emergentes até nomes já consagrados, de artistas populares aos mais contemporâneos”. A programação incluiu a cultura indígena, passando pelo "folclore", até a "vanguarda", e havia no projeto curatorial a preocupação com a "recriação da tradição cultural local em relação aos valores universais...". ${ }^{14}$ Em São Paulo, existem outros locais, "alternativos", de apresentação de danças tradicionais, como as três festas anuais realizadas por integrantes de um grupo de projeção de danças/músicas maranhenses, denominado Cupuaçu, que apresenta o auto do bumba meu boi e outras danças em uma praça de um bairro conhecido como Morro do Querosene, na zona Oeste da cidade. Para o local, nos dias das festas, acorrem milhares de interessados, principalmente jovens, que permanecem noite adentro assistindo as apresentações deste Grupo e de outros de mesmo tipo.

Uma outra referência, singular, da onda etnicista em diversos setores é o bufê infantil Casa Tupiniquim: Festas e Afins (casa especializada em organizar festas), inaugurado em outubro de 2000, em um bairro da zona Oeste (Vila Madalena), da cidade de São Paulo, que se promovia como um "Centro Cultural Infantil", voltado para "resgatar a cultura brasileira". No material impresso de divulgação, explicavam que ali, nas festas infantis, Mickey Mouse e outros personagens da mídia de massa "não entram". O trabalho de entretenimento das festas se fazia com lendas (Saci, Iara e outros), músicas, jogos/brincadeiras, danças e também com comidas "brasileiras".

\section{Praticantes das músicas e danças}

No que se refere aos grupos e artistas que se dedicam às manifestações tradicionais que aqui tratamos, podemos identificar inúmeras formações e propósitos, como: 1) os grupos tradicionais, comumente identificados como folclóricos ou tradicionais; 2) os balés folclóricos ou populares; 3) os intérpretes de músicas de tradição oral (folk singer); 4) os compositores de música popular, de gêneros regionais ou "de música raiz", conforme se costuma denominar no Brasil; e, 5) os grupos contemporâneos de vitalização das expressões populares.

Os grupos tradicionais são os continuadores das heranças dos antepassados. São as expressões de músicas, danças, rituais e festas que existem em milhares de comunidades, que são as referências para outros grupos que as imitam. É impor- 
tante destacar que nesses casos, na grande maioria das vezes, essas manifestações estão relacionadas a rituais, cerimoniais, de devoção, em festividades religiosas. Não se trata de atividades de interesse apenas estético, artístico. Os balés folclóricos são grupos de projeção estética, identificados como parafolclóricos, que mimetizam uma grande quantidade de danças e músicas dos grupos tradicionais, reproduzindo alguns dos seus aspectos apenas. Muitos deles se formaram no Brasil, em várias localidades, principalmente entre as décadas de 1960 e 1970, como: Teatro Popular Brasileiro, identificado à época como "Teatro Folclórico", fundado pelo ativista negro e poeta Solano Trindade, e por Maria Margarida da Trindade, em 1950, no Rio de Janeiro, e que se transferiram, em 1961, para a cidade do Embu, São Paulo; "Conjunto Folclórico da Bahia” (Viva Bahia), fundado em 1962, em Salvador, Bahia, por Emília Biancardi Ferreira; “Grupo Abaçaí - Balé Folclórico de São Paulo", criado em 1973, por Toninho Macedo; "Balé Popular do Recife", fundado em 1977, na cidade do Recife, além de outros tantos. ${ }^{15}$ Os intérpretes de músicas folclóricas são aqueles que apenas executam músicas da tradição oral, como fazem as cantoras Inezita Barroso e Ely Camargo. Os compositores de música de "raiz" são criadores e não reprodutores das músicas folclóricas, como as anteriores. Compõem, porém, inspirados nos padrões da tradição oral, havendo inclusive aqueles que também gravam músicas tradicionais. São diversas as nuanças desse tipo de compositor popular. Mais recentemente criou-se um estilo classificado como música de fusão (fusion), que se baseia na música tradicional, mas, muitas vezes, com tratamento pop, incorporando, inclusive, instrumentos musicais como a guitarra e o contrabaixo elétricos, a bateria, os teclados e outros. Alguns fazem uso de instrumentos tradicionais e "modernos" ao mesmo tempo. No geral, são classificados como músicos de MPB (música popular brasileira). Finalmente, existem os grupos contemporâneos de vitalização de músicas e danças tradicionais, que surgiram principalmente na década de 1990. À maneira dos grupos propriamente tradicionais, dedicam-se de modo específico a um só tipo de expressão ou a algumas poucas variedades apenas. Procuram, reproduzir os modelos nos quais se baseiam de modo mais especializado e profundo (diferentemente dos balés folclóricos). O exemplo pode ser o Grupo Cachuera!, da capital paulista, que surgiu em 1996, sob a liderança do músico e pesquisador Paulo Dias, reproduzindo os grupos denominados Moçambique e Congada, de Minas Gerais, principalmente. Vale mencionar também exemplos como o do dançarino e multi-instrumentista Antonio Nóbrega, que cria espetáculos integrados de música, teatro e danças com base nas tradições populares nordestinas, sobretudo de Pernambuco. Nóbrega se fixou em São Paulo em 1983. Não desenvolve apenas o trabalho de reprodução. Do mesmo modo, no caso da cultura caipira, podemos lembrar as atividades do compositor e violeiro Ivan Vilela, pesquisador e professor da Escola de Comunicações e Artes da USP, que faz trabalho autoral e como intérprete, a partir das referências da cultura caipira. Por sua vez, o Grupo A Barca, de 1998, de São Paulo, apenas interpreta as músicas da tradição oral, com instrumental que inclui piano, violão, percussão, contrabaixo e outros. 
Nesse movimento recente de vitalização das músicas, danças e rituais populares, em cada região do Brasil buscou-se destacar e visibilizar as próprias manifestações locais, seja uma congada em Minas Gerais ou em São Paulo; um bumba meu boi, em Pernambuco; uma roda de jongo no Espírito Santo ou Rio de Janeiro; um tambor de crioula, no Maranhão; um Fandango no Paraná, e assim por diante.

\section{O fomento ou a devoração, na sociedade civil}

Desde a década de 1990, alguns produtores culturais, educadores e pesquisadores, organizados em ONG, associações, cooperativas, coletivos e outros tipos de organização travam acirrada disputa pela hegemonia no que se refere às questões que envolvem as culturas populares, como um campo de atuação política e profissional. Tudo resulta do interesse que essas passaram a despertar nos últimos anos em diversos setores culturais, das artes, do turismo, da educação e inclusão social e dos governos, em todas as esferas, alcançando até empresas privadas, mobilizando recursos financeiros significativos. Há interesses que vão desde a obtenção de recursos financeiros para a simples organização de eventos e apresentações de músicas e danças populares como prática artística, assim como busca-se aproximação com políticos, secretários de Estados, prefeitos e empresas patrocinadoras, na busca de domínio do setor, com tentativas até de propor e interferir politicamente na aprovação e regulamentação de leis que se voltem para o fomento e a salvaguarda das expressões das culturas populares. Isso pode ser aferido pela criação em São Paulo do Fórum de Culturas Populares, depois Fórum Permanente de Cultura Popular Tradicional (FPCP), em agosto de 2002, que passou a reunir expressivo número de "associados" em todo o Brasil, inclusive de algumas organizações que realizam algum tipo de trabalho voltado para/ou com as culturas populares, a exemplo das ONG. Nota-se que o Fórum não só realizou reuniões e eventos de grande porte para tratar dos assuntos pertinentes, como também direcionou muito as preocupações para buscar meios de interferir politicamente (nas esferas federal, estaduais e municipais) com propostas direcionadas para as culturas populares, intermediando o setor público e os grupos e líderes das manifestações culturais. Criaram, inclusive, uma rede de comunicações via internet na qual anunciam e trocam informações sobre eventos relacionados ao tema. Entre $1^{\circ}$ e 6 de outubro de 2013, com apoio do Ministério da Cultura e do Sesc-SP, também o Fórum realizou o "Encontro de Culturas Populares e Tradicionais", no Sesc Itaquera, formalmente organizado agora como Fórum para as Culturas Populares e Tradicionais. A programação incluiu apresentações de grupos de música e dança de todo o Brasil e de artesanato e gastronomia regional, inclusive de comunidades indígenas. Realizaram ainda discussões visando ações de cunho político relacionadas às culturas populares. Na abertura, o evento teve a presença da ministra da Cultura Marta Suplicy e de representantes de diversos segmentos envolvidos nos temas tratados.

No ano 2013, travava-se intensa disputa principalmente entre o Fórum para as Culturas Populares e Tradicionais, com sede em São Paulo, e o grupo 
identificado como Ponto de Cultura Grão de Luz e Griô, oficializado em 2005, com apoio do Ministério da Cultura. O histórico de atividades desse segundo grupo vinha desde 1993, na cidade de Lençóis, na Bahia, e em 2006 propuseram a Ação Griô Nacional, ${ }^{16}$ para aprovação de um Projeto de Lei voltado às culturas populares tradicionais e seus "mestres", do mesmo modo como também o Fórum citado defendia um outro Projeto de Lei, estando ambos os grupos representados e apoiados por diferentes deputados federais.

A criação do Fórum motivou o desdobrar desse tipo de organização em inúmeros estados e municípios (fóruns estaduais e municipais), assim como a organização de associações, cooperativas, e outras formas de legalização institucional para o trato com as expressões populares de cultura. ${ }^{17}$

Além dessas iniciativas, também houve grande dinamização de iniciativas oficiais, no âmbito do governo federal, dos estados e municípios, na promoção das ações de fomento, registro e acautelamento das culturas tradicionais, corroboradas nos próprios documentos conceituais da Unesco, cujo objetivo principal é a "salvaguarda" dessas, ${ }^{18}$ que enfocamos em seguida.

\section{Legislações e normatizações oficiais}

Da legislação federal mais recente podemos destacar a própria Constituição Brasileira, de 1988, que prevê no seu Art. 215, Parágrafo 1 ${ }^{\circ}$ : “O Estado protegerá as manifestações das culturas populares, indígenas e afro-brasileiras, e das de outros grupos participantes do processo civilizatório nacional". No Art. 216, no que interessa para o presente enfoque, se lê:

Constituem patrimônio cultural brasileiro os bens de natureza material e imaterial, tomados individualmente ou em conjunto, portadores de referência à identidade, à ação, à memória dos diferentes grupos formadores da sociedade brasileira, nos quais se incluem: I - as formas de expressão; II - os modos de criar, fazer e viver;

E no Parágrafo $1^{\circ}$ :

O poder público, com a colaboração da comunidade, promoverá e protegerá o patrimônio cultural brasileiro, por meio de inventários, registros, vigilância, tombamento e desapropriação, e de outras formas de acautelamento e preservação.

No desdobramento do que preconiza a Constituição, corroboradas pelas propostas da Unesco, ${ }^{19}$ no ano 2000 foi oficializado o Decreto n.3.551 [Federal], de 4 de agosto, que:

Institui o Registro de Bens Culturais de Natureza Imaterial que constituem o patrimônio cultural brasileiro, cria o Programa Nacional do Patrimônio Imaterial $[\ldots]$ [no qual se prevê o registro nos] seguintes livros: I - Livro de Registro dos Saberes, onde serão inscritos conhecimentos e modos de fazer enraizados no cotidiano das comunidades; II - Livro de Registro das Celebrações, onde serão inscritos rituais e festas que marcam a vivência coletiva do trabalho, da religiosidade, do entretenimento e de outras práticas da vida 
social; III - Livro de Registro das Formas de Expressão, onde serão inscritas manifestações literárias, musicais, plásticas, cênicas e lúdicas; IV - Livro de Registro dos Lugares, onde serão inscritos mercados, férias, santuários, praças e demais espaços onde se concentram e reproduzem práticas culturais coletivas.

No sítio do Programa Nacional do Patrimônio Imaterial, do Instituto do Patrimônio Histórico e Artístico Nacional (Iphan) (Ministério da Cultura), nas suas diretrizes, propõe-se, entre outros aspectos: "Promover a inclusão social e a melhoria das condições de vida de produtores e detentores do patrimônio cultural imaterial", e, "Ampliar a participação dos grupos que produzem, transmitem e atualizam manifestações culturais de natureza imaterial nos projetos de preservação e valorização desse patrimônio", o que revela preocupações não somente com os fatos culturais em si, como sempre se fez historicamente, e, ainda predomina na maioria das propostas contemporâneas de fomento às culturas tradicionais. Nota-se, então, a preocupação com a valorização dos próprios detentores desses saberes, ${ }^{20}$ fato esse que se confirma também em outro sítio (dos Planos de Salvaguarda), no qual, se busca, "atuar no sentido da melhoria das condições sociais e materiais de transmissão e reprodução que possibilitam sua existência", que "podem ir desde a ajuda financeira a detentores de saberes específicos com vistas à sua transmissão, até, por exemplo, a organização comunitária ou a facilitação de acesso a matérias primas". ${ }^{21}$

Da mesma forma, multiplicaram-se no Ministério da Cultura outras iniciativas no tocante às culturas populares, entre as quais: Os Pontos e Pontões ${ }^{22}$ de Cultura, de "repasse de recursos em dinheiro e de ações do Programa Cultura Viva" (MinC), que no primeiro Edital, de 2004, selecionou aproximadamente 260 projetos, dos quais muitos voltados para as culturas populares tradicionais; o I Seminário Nacional de Políticas Públicas para as Culturas Populares, em fevereiro de 2005 (precedido de seminários em vários Estados); o Edital de Concurso Público n.2, de 31 de agosto de 2005, da Secretaria da Identidade e da Diversidade Cultural (SID)/Secretaria de Fomento e Incentivo à Cultura, para Fomento às Expressões das Culturas Populares, que teve em torno de 630 inscrições e selecionou 46 projetos de todo o País; ${ }^{23}$ o Prêmio Cultura Viva, em 2006; o Edital de Divulgação n.001/2006, de Mapeamento e Documentação do Patrimônio Cultural Imaterial, do Iphan-MinC, ${ }^{24}$ e, em setembro de 2006, o II Seminário Nacional de Políticas Públicas para as Culturas Populares e o I Encontro Sul-Americano de Culturas Populares.

Além das iniciativas de âmbito federal, também governos estaduais e municipais, e, ainda, de associações da sociedade civil, que, de uma forma ou de outra, voltaram-se para o fomento e salvaguarda das suas respectivas tradições culturais. Em São Paulo, instituiu-se, em 2001, o Dia da Cultura Caipira (5 de agosto) e, em 2004, o Dia do Saci (31 de outubro), no âmbito Estadual. Na cidade de Botucatu, São Paulo, organiza-se o Festival Nacional do Saci (no qual se criou a Associação Nacional dos Criadores de Saci); além disso, o governo do estado oficializou, em 2006, editais de Concurso de Apoio a Projetos de 
Promoção da Continuidade da Cultura Caipira, Caiçara, Piraquara e Afro, e, ainda, da Cultura Quilombola. ${ }^{25}$ Por sua vez, antes, o governo do Estado de Pernambuco, com base em Lei de 2002, promoveu em 2005 o I Concurso Público do Registro do Patrimônio Vivo do Estado de Pernambuco - RPV - PE para "beneficiar os artistas e mestres da cultura popular e tradicional do Estado", ${ }^{26}$ que passaram a ter direito a uma pensão mensal, como "Patrimônio Vivo". Igualmente, o governo do Estado do Ceará, já antes, em 2003, instituiu o Registro dos Mestres da Cultura Tradicional Popular do Estado do Ceará, os quais, selecionados, também obtiveram direito a um "auxílio financeiro" mensal como "Tesouro Vivo" do Ceará. ${ }^{27}$ Vários outros estados e municípios seguiram o mesmo exemplo promovendo e fomentando as suas próprias expressões tradicionais.

Há de mencionar também os empreendimentos de patrocínio, de grande importância, da Petrobras, empresa estatal, sobretudo desde a consolidação, em 2003, do Programa Petrobras Cultural, executado a partir de 2004, em sintonia com o Ministério da Cultura e a Secretaria de Comunicação de Governo e Gestão Estratégica, da Presidência da República, que entre as suas "linhas de atuação", no de Preservação e Memória (Música e Patrimônio), teve desmembramento de incentivo para projetos de Patrimônio (Memória das Artes e Patrimônio Imaterial), nas quais têm sido selecionados muitos projetos voltados para as culturas populares tradicionais. Da mesma forma, outras empresas, inclusive bancos, no sistema de renúncia fiscal, têm realizado ações semelhantes.

\section{Para concluir}

Revelados o interesse e a presença das expressões das culturas populares tradicionais, sobretudo de músicas, danças e aspectos plásticos, na dinâmica cultural contemporânea, considerando-se também seus aspectos conceituais, as legislações e iniciativas de reconhecimento, fomento e salvaguarda a elas destinadas, precisamos agora, para finalizar, trazer algumas reflexões que discutam o fenômeno. Trata-se, sim, de um movimento de amplas proporções que alcança vários setores da sociedade, desdobrando-se principalmente no campo das artes, da estética e da educação, do meio ambiente e da inclusão social, chegando à produção cultural e à política. Nesse último aspecto, já estão estabelecidas as bases de uma política de estado para o setor, conforme previsto na Constituição Federal e já com outras legislações regulamentadas, assim como outros projetos de lei e normatizações estão em processo de discussão, no Poder Executivo e no Legislativo, para incentivo e preservação das manifestações em si e dos seus líderes e portadores.

As questões suscitadas diante do tema são muitas e não há como respondê-las todas, no limite deste pequeno escrito. Temos, sim, consciência da fragilidade de algumas reflexões que trazemos, até porque estamos dialogando pouco com outros autores que já escreveram sobre o assunto, mas alguma contribuição pode existir mesmo deixando em aberto a busca de respostas aprofundadas. 
Tomo, então, emprestado partes de um texto que já publiquei sobre o assunto (Ikeda, 2007), para rediscutir alguns aspectos. Algumas questões: O que motiva o movimento de fascínio contemporâneo pelas culturas populares e tradicionais? A quem interessa? Quais as consequências das diversas iniciativas de suposto fomento e apoio para os grupos e portadores tradicionais desses saberes tradicionais? Outras tantas perguntas vão surgindo mas enfoco apenas alguns aspectos para contribuir com o tema.

Evidentemente, respostas únicas não caberão para as perguntas colocadas, mesmo porque não estamos aqui defendendo uma tese. De fato, são múltiplas as possibilidades de respostas, tanto no que se refere às motivações ou às consequências das ações que identifiquei como movimento ou onda etnicista.

No que toca às motivações, podemos acreditar que existem preocupações de mérito, lastreadas em disposições e preocupações sinceras de fomento e salvaguarda dos saberes populares tradicionais e dos indivíduos e suas comunidades guardiãs. Outros podem ver nessas expressões uma espécie de arte alternativa aos produtos de massa, embora também para consumo apenas, talvez sob a influência do movimento internacional da world music, que não deixa de ter base nos interesses comerciais, como oferecimento de produtos para atender um nicho específico do mercado, para pessoas mais intelectualizadas. Setores e pessoas podem estar ainda preocupados com a questão da identidade nacional diante da globalização, à maneira do movimento folclórico no século XIX. De qualquer modo, em uma visão dialética e macroestrutural, se admitirmos que esses fatos culturais estão ligados a grupos subalternos e periféricos da sociedade, todas as iniciativas, mesmo as governamentais, e até as artísticas e de inclusão social acabam resultando em processos que de algum modo chegam às apropriações e expropriações culturais, ${ }^{28}$ ou na transformação de conteúdos e sentidos sociais e políticos, sobretudo quando servem para preencher programações como espetáculos artísticos em instituições culturais, ou mesmo em apresentações oficiais organizadas por órgãos públicos, como referências da cultura nacional. Afinal, o simples ato da transposição desses fatos culturais de seus locais convencionais de realização (comumente inseridos em festas e rituais tradicionais) para outros transforma a atividade em uma simples representação, uma apresentação apenas.

Outro aspecto é que ocorre também algum tipo de apropriação quando os corriqueiros mediadores (produtores culturais, pesquisadores, professores e outros) acabam se tornando intermediadores dos grupos tradicionais com os órgãos públicos e privados, para o encaminhamento de projetos diversos para a obtenção de apoio financeiro, transformando-se em uma espécie de empresário desses, pressupondo, evidentemente, ganhos como profissional especializado ou como produtor cultural, que, quando exorbitam, transformam-se mesmo em "atravessadores" da cultura popular, no pior sentido. São muitos os "intelectuais" que acabam assumindo funções desse tipo, sobretudo diante dos detalhes burocráticos perante os órgãos governamentais e empresas privadas, na busca dos recursos financeiros para a sobrevivência das atividades. 
Quanto aos órgãos governamentais, mesmo quando corroboram as propostas normativas da Unesco para o setor, apesar, no geral, das posturas mais desinteressadas quanto ao aspecto comercial ou ao uso político dos conhecimentos tradicionais, podem também ocorrer expropriações e mudanças funcionais diante de suas ações. Tem sido comum, por exemplo, no âmbito do governo federal e de alguns estados, o oferecimento de Prêmios ${ }^{29}$ (em dinheiro) aos líderes e grupos que atuam com músicas, danças e rituais exigindo-se dos beneficiados a chamada contrapartida, comumente na forma de apresentações em público, visando dar maior visibilidade aos mesmos. Porém, tal procedimento apenas revela desconhecimento da essência de muitas dessas expressões, que podem ter escopo devocional, não se prestando como espetáculo, para palcos. São, muitas delas, práticas religiosas, mesmo tendo danças ao som de violas e cantorias, como é o caso, por exemplo, da Dança de São Gonçalo, que ocorre em várias localidades do Brasil, em diferentes formatos. $\mathrm{O}$ mesmo se verifica com os rituais da tradição religiosa afro-brasileira. Assim, também propostas de governos, mesmo sob a chancela do fomento e da salvaguarda, podem ser bem equivocadas e pautadas por vícios conceituais, resultantes de visões reducionistas, fragmentadas, e por demais generalizadas das culturas populares. ${ }^{30}$ Nesses casos, também não se levam em consideração os conceitos, as visões, os interesses, funções e sentidos mais profundos que as próprias comunidades têm dos fenômenos que praticam, preocupando-se predominantemente com as suas exterioridades, com os seus formatos. Entretanto, inúmeros líderes ou "mestres" tradicionais conseguem distinguir bem as demandas que os envolvem, preservando as funções e os sentidos mais profundos dessas práticas no seio das suas comunidades, dentro dos princípios herdados e mantidos por gerações. Sem dúvida, existe em alguns casos uma sabedoria no processo de guarda desses saberes ancestrais, independente das políticas e outras formas de ação de grupos externos.

De fato, no geral a forma como governos, instituições culturais, produtores culturais e mesmo pesquisadores promovem e apoiam as expressões da cultura popular é predominantemente pela via estética, compreendendo-as como arte ou entretenimento. Essas têm sido, historicamente, as maneiras como os grupos dominantes da sociedade conseguem reconhecer e admitir essas expressões. Por sua vez, sendo esse o modelo que se propõe, também os próprios grupos acabam assumindo-se como "artistas populares", como atração turística ou como "brincadeiras", embora nunca sejam valorizados pecuniariamente como profissionais, verdadeiramente. Esses grupos são comumente compostos por muitas pessoas (vinte, trinta ou bem mais) e recebem verbas que quando muito auxiliam na manutenção das roupas, instrumentos e outros adereços, sem que se chegue, nunca a uma contrapartida financeira real, que necessitam. Também, é comum, ainda, que sejam apresentados como fatos folclóricos, representando a identidade nacional (brasilidade) ou as localidades onde estão estabelecidos. ${ }^{31}$ Esse último tipo de intervenção é comum quando se escolhem as manifestações tradicionais como atrações artísticas ou turísticas de representação do país, do 
estado (folclore da Bahia, por exemplo), compreendendo-os como fenômenos isolados dos seus contextos históricos e sociais que lhes dão sentido. Por exemplo, um mestre de folia de reis, que é uma espécie de líder espiritual, religioso, devoto e representante dos três reis magos (Baltazar, Gaspar e Melchior), do catolicismo popular, passa a ser visto como representante do folclore brasileiro ou fica incluído na categoria de "artista popular" ou "brincante", o que, sem dúvida, é algo estranho para o próprio. Naturalmente, não se podem desconsiderar os aspectos estéticos e lúdicos que também integram a maioria das expressões populares tradicionais, geralmente com músicas, danças e representações dramáticas (rituais), mas que não são essas as suas essências para os próprios participantes, mesmo que sejam nomeadas popularmente como "brincadeiras". Assim, nem tudo nas culturas tradicionais pode se transformar, generalizadamente, em espetáculo artístico ou deve servir à "geração de renda", à maneira das preocupações utilitaristas, sobretudo governamentais, embora, obviamente, não se defenda aqui qualquer visão purista ou ingênua desses grupos, nem a intocabilidade desses.

Há de considerar que os fenômenos das culturas tradicionais guardam valores morais, religiosos, políticos, lúdicos, estéticos e outros tantos herdados, e que, portanto, de alguma forma, refletem a própria história das suas comunidades, repondo o passado no presente, e sendo então sempre atuais. São práticas aglutinadoras, que repetidas ciclicamente reforçam os valores socialmente aceitos e importantes para os grupos e indivíduos, vitalizando-os. Por serem fatos preservados e geridos coletivamente, são sempre práticas de identificação e inclusão social, e, até mesmo, de resistência política diante dos problemas que as comunidades enfrentam, assim como fazem frente à avalancha comunicacional cotidiana a que estão submetidas.

Assim, ações de fomento e salvaguarda, ${ }^{32}$ sem exigências de contrapartidas esdrúxulas, serão eficientes e mais interessantes na medida em que se pautem pelo conhecimento profundo e sensível das comunidades e das modalidades enfocadas, e sobretudo quando levam em consideração também as visões e essências das próprias populações envolvidas, cuja autogestão é fundamental, desvinculando-se de mediadores (muitas vezes, "atravessadores"), que estabelecem com os grupos praticantes dos saberes tradicionais inúmeras formas de relacionamento, paternalistas ou exploradoras comercialmente, quando das suas vorazes inserções (devorações, leia-se) no mundo contemporâneo da cultura como espetáculo e entretenimento.

\section{Notas}

1 As ONG proliferaram a partir de 1985, com a redemocratização do Brasil, encerrada a ditadura militar (1964-1985) e o início das políticas neoliberais, com significativo aumento na década de 1990. 
2 Evidentemente, essas preocupações não são exclusivas do Brasil, tendo alcance mundial, afinal descobre-se talvez um tanto tardiamente que o mundo é um só.

3 Há anos o termo folclore tem sido evitado por muitos estudiosos, por seu desgaste semântico. Um dos motivos dessa deterioração se deu pela maneira como os fatos culturais populares, tradicionais, foram concebidos, estudados e divulgados por muitos folcloristas: de modo descontextualizado, considerados apenas em aspectos fragmentados das expressões em si, nas suas exterioridades e formas, independentemente das suas funções e sentidos profundos para as pessoas e comunidades onde se preservam. Nesse viés, acabavam servindo como alegoria e representação da cultura nacional, da brasilidade, ou das regionalidades, ou ainda como manifestações de arte, para o usufruto estético e de entretenimento. Tais enfoques provocaram nas pessoas visão negativa a respeito desses fatos, como se fossem expressões curiosas, rústicas, anedóticas, exóticas diante da vida moderna, vinculados aos ignorantes e à pobreza. $\mathrm{O}$ folclore se prestava a exaltação romântica e reconhecimento do "povo" brasileiro, como referência da identidade da nação. O sociólogo Florestan Fernandes, desde a década de 1940, alertava para as questões epistemológicas relacionadas aos estudos do folclore, em diversos artigos publicados em jornais e revistas, como: "Folclore e Ciências Sociais" (1959); "Objeto e campo do folclore" (1958); "Folclore e sociedade" (1960); "O folclore como método" (1944) e outros, que podem ser encontrados em Fernandes (1961). Ver, também, Vilhena (1997).

4 Ver: <http://portal.iphan.gov.br/portal/montarPaginaSecao.do?id=12553\&retorno =paginaIphan $>$. No âmbito internacional, no ano 2003, a Unesco aprovou a "Convención para la salvaguardia del patrimonio cultural inmaterial", Paris, 17 de octubre de 2003, conforme se vê em: <http://www.unesco.org/culture/ich_convention/index.php?pg=000228\&PHPSESSID=ebb128633fa78faec3df3b29761829c5>.

5 Para mais detalhes, ver Ortiz (1985). No Brasil, historicamente, desde os estudos pioneiros "de folclore" (de literatura oral), do escritor sergipano Ś́lvio Romero (18511914), com o livro Cantos populares do Brasil, publicado em 1883, reunindo contos, cantos e poesias populares, várias foram as iniciativas de reconhecimento da importância das culturas populares tradicionais, sobretudo como indicadoras da brasilidade. Oficialmente, diversas foram as iniciativas para se documentar, estudar e fomentar os saberes das culturas tradicionais. Podemos citar: a Missão de Pesquisas Folclóricas, iniciativa de Mário de Andrade, em 1938, no então Departamento de Cultura do Município de São Paulo, que fez extenso registro (gravações, fotos, registro descritivo) de manifestações populares do Norte e Nordeste do Brasil; a criação da Comissão Nacional de Folclore (CNFL) em 1947, organizada no Ministério das Relações Exteriores, como representante do Brasil na Unesco; e a criação da Campanha de Defesa do Folclore Brasileiro em 1958 (atualmente Centro Nacional de Folclore e Cultura Popular, do Instituto do Patrimônio Histórico e Artístico Nacional, do Ministério da Cultura), criado para: "promover registro, pesquisas e levantamento, cursos de formação e de especialização, exposições, publicações, festivais; proteger o patrimônio folclórico, as artes e os folguedos populares; organizar museus, bibliotecas, filmotecas, fonotecas e centros de documentação; manter intercâmbio com entidades congêneres; divulgar o folclore no Brasil". Em 1965, instituiu-se a data de 22 de agosto como o Dia do Folclore, no âmbito do governo federal, decreto no qual se expunha: "O Governo deseja assegurar a mais ampla proteção às manifestações da criação popular não só estimulando sua investigação e estudo, como ainda defendendo a sobrevivência dos seus folguedos e artes, como elo valioso da continuidade tradicional brasileira...". 
6 É interessante perceber que tanto do ponto de vista conceitual quanto em relação às preocupações com a salvaguarda e o fomento desses saberes, o que se propõe atualmente se parece, em muitos aspectos, com o que se propunha no século XIX, apesar das especificidades de cada um desses momentos.

7 Conf. "Recomendação sobre a salvaguarda da cultura tradicional e popular", tradução do autor, disponível em: <http://www.unesco.org/culture/laws/paris/html_sp/ pagel.shtml>, acesso em: 17 maio 2006.

8 Traduzido da "Convención para la salvaguardia del patrimonio cultural inmaterial", Unesco, Paris, 17 de octubre de 2003. Disponível em: <http://www.unesco.org/ culture/ich_convention/index.php?pg=000228\&PHPSESSID=ebb128633fa78faec 3df3b29761829c5>. Acesso em: 19 ago. 2006.

9 Sobre as peculiaridades dos “fatos folclóricos", ver Pellegrini Filho (1982, p.11-33) e Carvalho (1992, p.13-21).

10 Inclusive, nas universidades, pode-se notar o surgimento de especializações relacionadas ao campo da antropologia, como a etnocenologia, etnopoesia, etnobotânica, etnomedicina, etnomatemática e outras.

11 Ver: <http://www.dw.de/encontro-europeu-de-maracatus-colore-as-ruas-de-col\% C3 \%B4nia/a-16120182-1>, divulgando o 5 Encontro Europeu de Maracatus, de 2012.

12 No Brasil, porém, no âmbito comercial, nas lojas, já se notava um refluxo no setor “discográfico" dessa vertente no início de 2004. Nas grandes lojas de São Paulo se podia verificar notória diminuição das sessões destinadas à "música do mundo", conforme observação que fizemos nas livrarias Cultura, Fnac e Saraiva. Além da diminuição dos títulos e estantes oferecidos, também a sessão mudou para local menos visível, nos fundos da loja, misturando-se também com CD da chamada música "new age" e de alguns artistas da Música Popular.

13 Conf. título do CD duplo: Vozes de mundos esquecidos: música tradicional dos povos indigenas, compilado e editado por Larry Blumenfeld, pela Ellipsis Arts..., Roslyn-New York, 1993, produzido "em colaboração com o Centro para os Direitos Humanos das Nações Unidas".

14 Conf. Programação "Balaio Brasil”, Sesc-São Paulo, 2000.

15 Exemplo de outros grupos de projeção artística: Godap - Grupo de Danças Parafolclóricas “Cidade Menina Moça”, de Olímpia, São Paulo, fundado em agosto de 1966; Grupo Folclórico Hispano-Brasileiro, fundado em 1966, no Estado do Ceará, transformando-se no Grupo de Tradições Cearenses (GTC) em 1975; Grupo Cazumbá, de Teatro e Dança, da cidade de São Luís, Maranhão, fundado em 1973; Teatro Popular Solano Trindade, iniciado em 1975, na cidade do Embu, próxima de São Paulo, por Raquel Trindade; Grupo Urucungo, Puítas e Quinjengues, "grupo de dança e teatro popular” surgido em 1988, em Campinas, São Paulo; Balé Folclórico da Bahia, da cidade de Salvador, Bahia, de 1988; além de muitos outros.

16 Disponível em: <www.acaogrio.org.br/apresentação/historico>.

17 Ver Vilhena (1997), para esclarecimentos a respeito das organizações que folcloristas realizaram desde a década de 1940, na formação da Comissão Nacional de Folclore e das Comissões Estaduais de Folclore, preocupados também com a "administração" desse campo de atuação. Muitas dessas Comissões ainda são atuantes, responsáveis por Congressos por todo o Brasil. 
18 Os documentos são, respectivamente: Recomendação sobre a Salvaguarda da Cultura Tradicional e Popular (1989) e Convenção para a Salvaguarda do Patrimônio Cultural Imaterial (2003).

19 Ver: 1972 - Convenção para a Proteção do Patrimônio Mundial, Cultural e Natural; 1989 - "Recomendación sobre la salvaguardia de la cultura tradicional y popular", Paris, 15 de novembro de 1989; 2003 - "Convención para la salvaguardia del patrimonio cultural inmaterial", Unesco, Paris, 17 de outubro de 2003. Disponível em: <http:// www.unesco.org/culture/ich_convention/index.php?pg=000228\&PHPSESSID=eb bl28633fa78faec3df3b29761829c5>.

20 Disponível em: <http://www.iphan.gov.br/bens/P.\%20Imaterial/imaterial.htm>. Acesso em: 16 abr. 2005.

21 Disponível em: <http://portal.iphan.gov.br/portal/montarPaginaSecao.do?id=1255 3\&retorno=paginaIphan $>$. Acesso em: 26 jun. 2006.

22 Que reúnem vários grupos ou Pontos.

23 Disponível em: <http://www.cultpopbrasil.org/noticias/news_item.2006-01-05. 01 46052683 >, em 28 maio 2006, e publicação: Cultura Viva - Programa Nacional de Cultura, Educação e Cidadania. 2.ed. Brasília: Ministério da Cultura; Ministério do Trabalho e Emprego, 2005.

24 Disponível em: <http://portal.iphan.gov.br/forum/concurso/novasede/Edital_PN PI-2006.PDF>. Acesso em: 30 jul. 2006.

25 Disponível em: <http://www.cultura.sp.gov.br/StaticFiles/SEC/edital/Edital_PAC _17-2006_cultura_caipira.doc>. Acesso em: 27 jul. 2006.

26 Ver sítio Fundarpe.

27 Disponível em: <http://www.cultpopbrasil.org/politicaspublicas/document.200506-27.1565947118>. Acesso em: 28 maio 2006. O conceito de "Tesouro Nacional Vivo" foi iniciado no Japão, na década de 1950, e posteriormente alcançou outros países, sendo também incorporado pela Unesco, no projeto dos “Tesouros Humanos Vivos", servindo de referência para vários países.

28 O antropólogo e etnomusicólogo José Jorge de Carvalho trata do assunto em diversos textos, que podem ser encontrados nos sítios de procura da internet, um dos quais está indicado na nota 32 deste ensaio, assim como o tema está tratado em Carvalho (2003).

29 Doação de recursos financeiros como apoio, sem a necessidade de prestação excessivamente burocrática de contas.

30 Há de reconhecer que a própria tentativa de nomear, com poucos termos (gerais), as tão variadas expressões culturais populares revela uma compreensão redutora, rasa, das mesmas. De fato, cultura popular é nomenclatura muito vaga e já saturada, praticamente sem eficácia representativa e conceitual.

31 Realmente, elas são expressões identitárias, porém tão somente dos próprios praticantes ou das comunidades nas quais se inserem. Elegê-los como representantes de uma Nação, um Estado ou um Município é algo que extrapola o fundamento existencial dos grupos, sem dúvida, sendo isto mais uma artimanha político-ideológica, de conferir a estes um suposto valor simbólico apenas, de "focrório brasileiro".

32 Sobre o assunto, ver Sant'Anna (2005); Vianna (2004, p.15-24); e Carvalho (2004, p.65-83). 


\section{Referências}

CARVALHO, J. J. de. La etnomusicología en tiempos de canibalismo musical. Uma reflexión a partir de las tradiciones musicales afroamericanas. Revista Transcultural de Música, n.7, 2003. Disponível em: <http://www.sibetrans.com/trans/redaccion. htm>.

Metamorfoses das tradições performáticas afro-brasileiras: de patrimônio cultural a indústria de entretenimento. In: Celebrações e saberes da cultura popular: pesquisa, inventário, crítica, perspectivas. Rio de Janeiro: CNFCP, Funarte; Iphah; MinC, 2004. p.65-83). (Série Encontros e Estudos, n.5).

CARVALHO, R. L. S. de. A antropologia e a crise taxonômica da cultura popular. In: Seminário Folclore e Cultura Popular: as várias faces de um debate. Rio de Janeiro: INF/IBAC/MinC, 1992, p.13-21.

DELLA MÔNICA, L. Mamual de folclore. São Paulo: AVB, 1976.

FERNANDES, F. Folclore e mudança social na cidade de São Paulo. São Paulo: Anhambi, 1961.

IKEDA, A. T. Manifestações tradicionais: rituais, artes, ancestralidades ... (Prêmio Cultura Viva, do MinC). In: CARRARA. A. R. (Coord.) Prêmio Cultura Viva: um prêmio à cidadania. São Paulo: Cenpec, 2007. p.50-54.

ORTIZ, R. Cultura popular: românticos e folcloristas. São Paulo: Programa de Estudos Pós-Graduados em Ciências Sociais / PUC-SP, 1985.

PELLEGRINI FILHO, A. Conceitos brasileiros de folclore. In: . (Org.) Antologia de Folclore Brasileiro. São Paulo: Edart; Universidade Federal da Paraíba; Universidade Federal do Pará, 1982. p.11-33.

SANT'ANNA, M. Políticas públicas e salvaguarda do patrimônio cultural imaterial. In: Registro e politicas de salvaguarda para as Culturas Populares. Rio de Janeiro: CNFPC-Iphan-MinC, 2005 (Série: Encontros e Estudos, n.6);

VIANNA, L. Patrimônio Imaterial: legislação e inventários culturais. A experiência do Projeto Celebrações e Saberes da Cultura Popular. In: Celebrações e saberes da Cultura Popular: pesquisa, inventário, crítica, perspectivas. Rio de Janeiro: CNFPC-Iphan-MinC, 2004. p.15-24. (Série Encontros e Estudos, n.5).

VILHENA, L. R. Projeto e missão: o movimento folclórico brasileiro, 1947-1964. Rio de Janeiro: Funarte; Getulio Vargas, 1997.

RESUMO - O ensaio propõe reflexões em torno da presença das culturas populares de tradição oral no cenário da cultura contemporânea do Brasil, a partir do ressurgimento de um intenso movimento de interesse por expressões de músicas, danças e festas tradicionais, sobretudo, no entremeio dos séculos XX e XXI.

PALAVRAS-CHAVE: Cultura popular, Folclore, Salvaguarda, Devoração cultural.

ABSTRACT - The paper proposes reflections about the presence of popular and traditional cultures in the scene of contemporary Brazil's culture, from the resurgence of a move- 
ment interested in expressions of music, dances and parties especially between the $20^{\text {th }}$ and $21^{\text {st }}$ centuries.

KEYWORDS: Popular culture, Folklore, Safeguard, Cultural devouring.

Alberto T. Ikeda é professor do Instituto de Artes, da Universidade Estadual Paulista "Júlio de Mesquita Filho" (Unesp - Campus de São Paulo).

@- atikeda@uol.com.br

Recebido em 16.10.2013 e aceito em 25.10.2013.

I Instituto de Artes, Departamento de Artes Cênicas Educação e Fundamentos da Comunicação, Universidade Estadual Paulista Júlio de Mesquita Filho. São Paulo/ SP, Brazil. 